\title{
Postural behaviour of intraocular pressure in diabetics
}

\author{
MOHINDER SINGH' AND SYLVIA CHIN SUET HEONG \\ From the Departments of ${ }^{1}$ Ophthalmology and ${ }^{2}$ Optometry, National University of Malaysia, Kuala Lumpur, \\ Malaysia
}

SUMMARY The response to posture of intraocular pressure (IOP) was studied in 58 normal and 60 diabetic eyes. A significant postural rise of IOP was found in the diabetic patients. The clinical relevance of the abnormality in pressure regulation in diabetics is discussed. Its implications for other closely associated disorders are emphasised.

Diabetes mellitus is now becoming one of the leading causes of blindness, especially in elderly people. Ocular complications of diabetes tend to increase in frequency with the duration of diabetes but bear little relation to the severity of the disease. The incidence of primary open-angle glaucoma is said to be higher in diabetic than in non-diabetic people, suggesting a close relationship between diabetes and this kind of glaucoma.' An abnormal postural response of the intraocular pressure (IOP) bilaterally has been reported in cases of unilateral central or tributary retinal vein occlusion. ${ }^{2}$ An abnormality of pressure regulation in these patients has been suggested. ${ }^{2}$ Such retinal vascular occlusions are more common than usual in diabetes mellitus ${ }^{2}$ and open-angle glaucoma. ${ }^{3}$ It was therefore decided to investigate the postural response of the IOP in diabetic patients because clinical data on this aspect of diabetes are surprisingly lacking.

\section{Materials and methods}

Thirty normal persons above the age of 40 years were

Correspondence to Dr Mohinder Singh, FRCS, Faculty of Medicine, National University of Malaysia, PO Box 22418, Kuala Lumpur, Malaysia. carefully selected from the Ophthalmic Clinic of University Kebangsaan, Malaysia. Thirty diabetic patients above the age of 40 years were also selected from the medical units of University Kebangsaan, Malaysia, and the General Hospital, Kuala Lumpur. There was no evidence of any inflammatory eye disease in the normal or diabetic individuals. Patients with significant respiratory or cardiovascular disease or with any family history of glaucoma were excluded. None of the normal subjects was receiving any systemic or local medication.

Perkins' hand-held applanation tonometer was used to measure the intraocular pressure (IOP) throughout this study. The subject was asked to sit in a chair. Both eyes were anaesthetised with $0.4 \%$ oxybuprocaine eye drops and were lightly stained with fluorescein dye. The IOP was measured first in the sitting position in each eye separately. The subject was then asked to lie down on the examination table. No pillows were given to support the head. After about five minutes the IOP was measured in the supine position in each eye. All measurements were done by the same observer (MS). An average of three measurements was taken as the final reading. Cases showing more than $2 \mathrm{mmHg}$ difference in IOP rise between the two eyes were not considered.

Table 1 Age and sex distribution

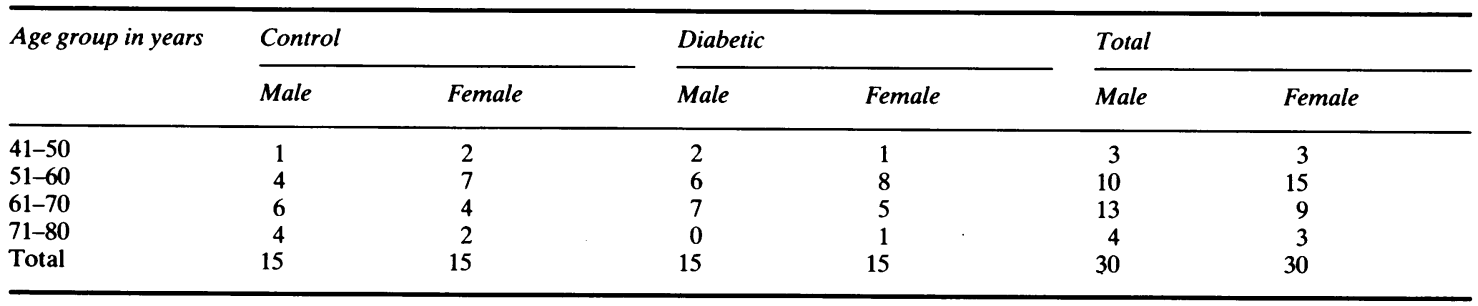




\section{Results}

A total of 60 diabetic and 58 control eyes were examined. The results are shown in Tables $1-3$ and Fig. 1.

Both groups were closely matched for age and sex. Most of the subjects were in the age range of 51-70 years.

The mean IOP readings in each group are shown in Table 2. The average sitting intraocular pressure (SIOP) of 14.14 (SD 3.56 ) $\mathrm{mmHg}$ was found in normal Malaysian eyes. The mean SIOP in the diabetic Malaysian eyes was noted to be 15.64 (SD 3.24) $\mathrm{mmHg}$. There was no significant difference in the two sexes in either group. An average rise of 1.82 (SD 0.50$) \mathrm{mmHg}$ in IOP on assuming the supine position was observed in normal, healthy individuals. The comparable figure of 3.58 (SD 0.51 ) $\mathrm{mmHg}$ was observed in the diabetic patients. A difference of 1.76 $\mathrm{mmHg}$ between the mean postural rise of IOP in the two groups was noted, which was statistically significant $(\mathrm{p}<0 \cdot 01)$.

An increase of $5 \mathrm{mmHg}$ or more in IOP with postural change was used to separate a group of 11 $(18.3 \%)$ diabetic eyes which registered a rise of more than $4 \mathrm{mmHg}$ in IOP on changing from the erect to the supine position (average $8.84 \mathrm{mmHg}$ ). The remaining $49(81.7 \%)$ diabetic eyes showed a rise of IOP of $0-4 \mathrm{mmHg}$ (average $3.49 \mathrm{mmHg}$ ). The IOP elevation in $56(96.6 \%)$ control eyes also varied between 0 and $4 \mathrm{mmHg}$, with an average of 1.82

Table 2 Average IOP measurements $(\mathrm{mmHg})$ in two groups ( $S D$ in parentheses)

\begin{tabular}{llll}
\hline & Sitting IOP & Lying IOP & IOP change \\
\hline Control & & & \\
Male (29 eyes) & $14 \cdot 68( \pm 3 \cdot 32)$ & $16 \cdot 48( \pm 3 \cdot 69)$ & $1 \cdot 79( \pm 0.54)$ \\
Female (29 eyes) & $13 \cdot 65( \pm 3 \cdot 8)$ & $15.00( \pm 4 \cdot 37)$ & $1 \cdot 85( \pm 0 \cdot 46)$ \\
Mean (58 eyes) & $14 \cdot 14( \pm 3 \cdot 56)$ & $15 \cdot 96( \pm 4 \cdot 00)$ & $1 \cdot 82( \pm 0 \cdot 50)$ \\
Diabetic & & & \\
Male (30 eyes) & $16 \cdot 11( \pm 3 \cdot 43)$ & $20 \cdot 02( \pm 3 \cdot 51)$ & $3.91( \pm 0.53)$ \\
Female (30 eyes) & $15 \cdot 17( \pm 3 \cdot 10)$ & $18 \cdot 42( \pm 3 \cdot 32)$ & $3 \cdot 25( \pm 0 \cdot 49)$ \\
Mean (60 eyes) & $15 \cdot 64( \pm 3 \cdot 24)$ & $19 \cdot 22( \pm 3 \cdot 31)$ & $3 \cdot 58( \pm 0 \cdot 51)$ \\
\hline
\end{tabular}

$\mathrm{mmHg}$. Only two (3.4\%) normal eyes showed a rise of $6 \mathrm{mmHg}$. There was no significant correlation between the abnormal postural rise of IOP and duration of diabetes. However, a greater rise of IOP was noted in comparatively elderly diabetic patients, though it was not statistically significant.

From Fig. 1 it can be seen that $82.4 \%$ (48 eyes) of the control eyes showed a rise of IOP up to $2 \mathrm{mmHg}$. A similar rise of IOP in the diabetic group was seen only in $38.4 \%$ (23 eyes). The highest IOP rise of 12 $\mathrm{mmHg}$ was observed in one eye of a 72-year-old diabetic woman.

\section{Discussion}

Diabetes mellitus, primary wide open-angle glaucoma, and retinal vascular occlusions are clinically closely linked. ${ }^{1-3}$ Both diabetes and open-angle glaucoma can be exacerbated by the administration of corticosteroids.' An abnormally high rise of IOP can be produced by topical steroids in both groups of patients. The effects of diabetes on IOP have been studied by many workers.' Jain and Luthra ${ }^{4}$ postulated that changes in blood glucose levels may affect the IOP, and that perhaps the pattern of intraocular tension, including the variability of its responsiveness to different stimuli, may be determined genetically and influence the retinopathy thereby. A moderate rise of IOP seems to protect against the development of diabetic retinopathy with haemorrhages, as observed in cases of glaucoma and diabetes. ${ }^{1}$ However, both diseases are thought to be interrelated genetically, as suggested by their steroid responsiveness. ${ }^{5}$ Hyperglycaemia together with a decreased $\mathrm{pH}$ lowers the IOP by increased serum colloid osmotic pressure.

A significant postural rise of IOP $(3.58 \mathrm{mmHg})$ was seen in our diabetic patients. Williams et al. ${ }^{6}$ also found a postural rise of $4.9 \mathrm{mmHg}$ in their small series of 14 diabetics. It seems that the level of IOP is not adequately controlled with change of body position in diabetic people. This abnormality is said not to be determined by coexisting systemic hypertension. ${ }^{\circ}$ Our study supports this observation, as none of our

Table 3 Comparison of age, sex, IOP measurements, and duration of diabetes in diabetic and control subjects

\begin{tabular}{lccc}
\hline & $\begin{array}{l}\text { I1 Diabetic eyes, IOP rise } \\
\text { more than } 4 \mathrm{mmHg}\end{array}$ & $\begin{array}{l}49 \text { Diabetic eyes, IOP rise } \\
0-4 \mathrm{~mm} \mathrm{Hg}\end{array}$ & $\begin{array}{l}56 \text { Control eyes, IOP rise 0-4 } \\
\mathrm{mmHg}\end{array}$ \\
\hline Average age in years & $61 \cdot 5$ & 59 & $56 \cdot 6$ \\
Male:female & $5: 6$ & $25: 24$ & $7: 7$ \\
Average SIOP mmHg & $15 \cdot 59$ & $15 \cdot 49$ & $14 \cdot 14$ \\
Average LIOP mmHg & $24 \cdot 43$ & $18 \cdot 98$ & $15 \cdot 96$ \\
Average IOP rise $\mathrm{mmHg}$ & $8 \cdot 84$ & $3 \cdot 49$ & $1 \cdot 82$ \\
Average duration of diabetes in years & $11 \cdot 7$ & $12 \cdot 34$ & \\
\hline
\end{tabular}

SIOP=sitting intraocular pressure. $\mathrm{LIOP}=$ lying intraocular pressure. 


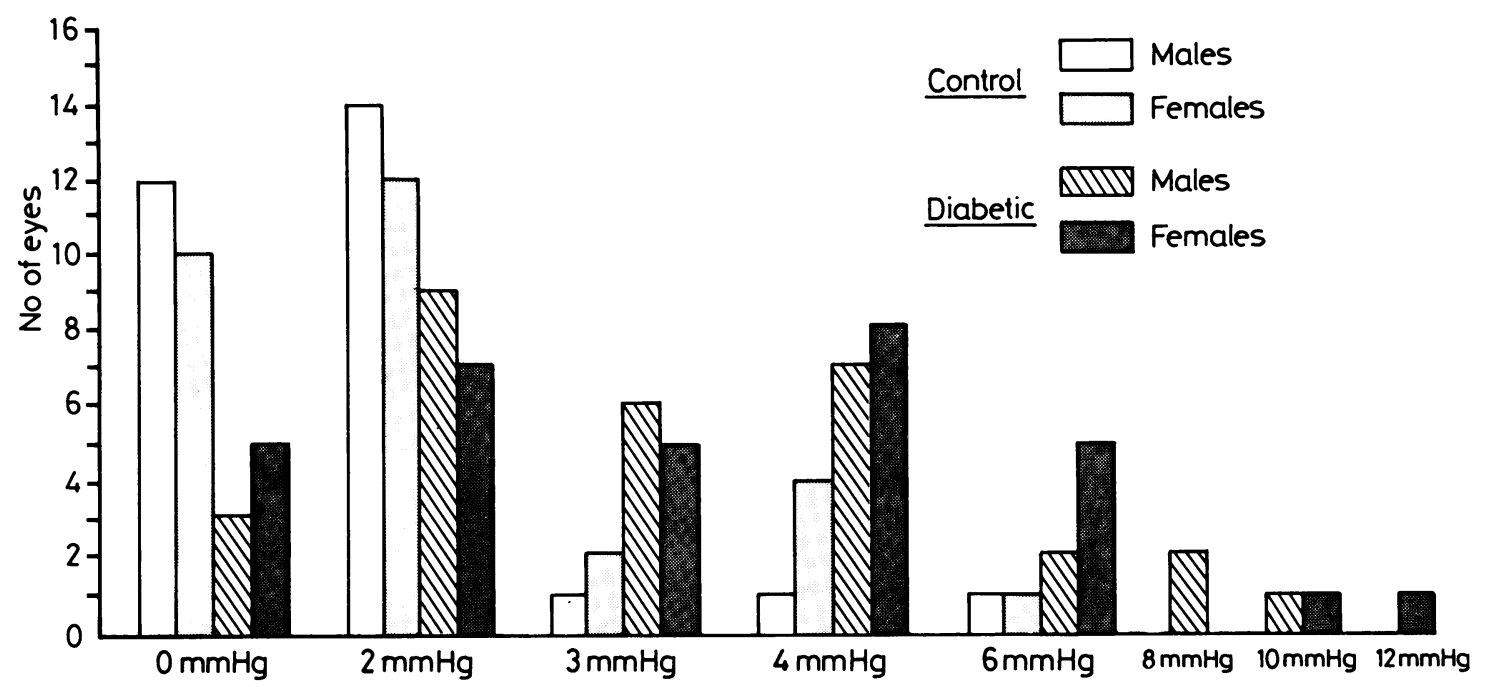

Fig. 1 Histogram of pressure differential between patients sitting and lying down. $P_{0}=L I O P-S I O P \mathrm{mmHg}$.

diabetic subjects had any significant hypertension and none was on antihypertensive medication.

Retinal vascular occlusions are said to be unusually common in diabetic as well as in chronic simple glaucoma. ${ }^{1}$ The risk of suffering such retinal vascular accidents increases in the presence of systemic hypertension. It has been suggested that in these cases the eyes may share a common defect which predisposes them to develop these abnormalities. ${ }^{6}$ No clinical test is entirely suitable for identifying those diabetic eyes which are at risk of developing vascular accidents and open-angle glaucoma. The abnormal postural response of the IOP may become a useful test for identifying such patients early. ${ }^{6}$

Reference to Table 3 shows that, while the mean rise of IOP in diabetic patients as a group may be higher than that of normal control subjects, all diabetic patients do not behave in a similar way. In $38.3 \%$ of our diabetic eyes the IOP rose by only 2 $\mathrm{mmHg}$ (Fig. 1). Eleven diabetic eyes in this study showed a postural rise of IOP of 5-12 $\mathrm{mmHg}$. Such a swing in a small number of diabetic eyes is rather striking. The exact mechanism of this anamolous behaviour is not understood. A similar higher postural response has been reported in ocular hypertensives.' These authors attributed it to the presence of more risk factors of chronic simple glaucoma in these patients, notably a family history of glaucoma. We have tried to exclude subjects with such a history. However, our subjective screening might have left some individuals with a genetic risk in the study.

In addition, local adrenergic receptors are said to be important for maintaining a stable IOP despite changes of posture. ${ }^{8}$ Inadequacy of this local regulatory mechanism might account for the pathogenesis of this abnormal response of the IOP, especially in diabetic patients, who are apt to develop autonomic neuropathy. ${ }^{9}$ In a few of our cases some degree of hypertensive asymmetry between the two eyes was observed $(2 \mathrm{mmHg})$. A considerable postural rise of IOP in one eye alone has already been reported in cases of ocular hypertension ${ }^{7}$ and unilateral chronic simple glaucoma." It seems to suggest there is an abnormality of pressure regulation locally within the eye in such patients.

In the present study no attempt was made to correlate the postural change of IOP with the type of diabetic retinopathy. Such a study would be useful to establish whether an abnormally high postural rise of IOP can protect the eye against the development of serious proliferative retinopathy. It is well known that a raised intraocular pressure is seen more commonly in diabetics with no proliferative changes than in non-diabetic persons or diabetic patients with proliferative retinopathy.' The optic nerve head is said to be more vulnerable to the IOP in diabetics.' As most of our diabetic patients are old, they may spend a considerable time lying supine while sleeping or otherwise, and they may thus possibly suffer optic nerve damage from an abnormality of pressure regulation. This may be relevant to the development of acute anterior ischaemic optic neuropathy in elderly people." But the disorder remains poorly understood, and the prognosis for vision generally is poor. Evaluation of the postural response of the IOP in cases of acute optic nerve ischaemia should receive serious consideration. A significant postural change of IOP has been recently reported in patients with low-tension glaucoma. ${ }^{12}$ It has been suggested that damage to the optic nerve in these cases might be 
occurring when the patient is actually asleep in the supine position. ${ }^{8}$ The postural response of the IOP should become an essential part of the overall assessment of diabetic effects on the eye.

The authors thank Professor Datuk Mohd Noor Marahakim for encouragement. We are grateful to Dr Mohinder Singh, consultant physician, for referring diabetic patients for study. We also appreciate the help of Puan Miskiah Ahmad in providing the references and Norul Amani Mohd Danin in typing the manuscript.

\section{References}

1 Becker B. Diabetes mellitus and primary open angle glaucoma. Am J Ophthalmol 1971; 71: 1-10.

2 Williams BI, Peart WS. Effect of posture on the intraocular pressure of patients with retinal vein obstruction. $\mathrm{Br} J$ Ophthalmol 1978; 62: 688-93.

3 Bertelsen RO. The relationship between thrombosis in the retinal vein and primary glaucoma. Acta Ophthalmol (Kbh) 1961; 39: 603-13.
4 Jain IS, Luthra CL. Diabetic retinopathy: its relationship with intraocular pressure. Arch Ophthalmol 1967; 78: 198-200.

5 Rimoin DL, Schimke RN. Genetic disorders of the endocrine glands. St Louis: Mosby, 1971: 150-216.

6 Williams BI, Peart WS, Letley E. Abnormal intraocular pressure control in systemic hypertension and diabetes mellitus. $\mathrm{Br} J$ Ophthalmol 1980; 64: 845-51.

7 Leonard TJK, Kerr Muir MG, Kirby GR, Hitchings RA. Ocular hypertension and posture. Br J Ophthalmol 1983; 67: 362-3.

8 Langham ME. Role of adrenergic mechanism in development and therapy of open angle glaucoma. Proc R Soc Med 1971; 64: 622-8.

9 Clark BF, Ewing DJ, Campbell IW. Diabetic autonomic neuropathy. Diabetologia 1979; 17: 195-212.

10 Inglima $R$. Effects of patient position on applanometer readings. Ear Nose Throat J 1968; 45: 64-9.

11 Hayreh SS. Acute ischaemic optic neuropathy. IV. Occurrence after cataract extraction. Arch Ophthalmol 1980; 98: 1410-6.

12 Tsukahara N, Sasaki T. Postural change of IOP in normal persons and in patients with primary wide open-angle and lowtension glaucoma. BrJ Ophthalmol 1984; 68: 389-92.

Accepted for publication 31 October 1985. 